\title{
Colorimetric Monitoring of a Chemical Reaction Using Cesium Lead Halide Assays
}

\author{
Tennyson L. Doane ${ }^{\dagger}$, Kevin J. Cruz-Lopez, Mathew M. Maye* \\ Department of Chemistry, Syracuse University, Syracuse New York 13244 U.S.A. \\ ${ }^{\dagger}$ Present Address: Department of Chemistry, Eastern Nazarene College, \\ Quincy, MA, 02170, U.S.A. \\ *mmmaye@syr.edu
}

\begin{abstract}
Cesium lead halide $\left(\mathrm{CsPbX}_{3}, \mathrm{X}=\mathrm{F}, \mathrm{Cl}, \mathrm{Br}, \mathrm{I}\right)$ nanomaterials have a number of novel optoelectronic and physical properties, both of which are tailorable based on halide type and concentration, such as halide composition-dependent photoluminescence and rapid halide exchange while maintaining crystal structure. In this work we take advantage of these properties and use colloidal $\mathrm{CsPbI}_{3}$ nanoparticles as a proxy and colorimetric sensor of a chemical reaction in real-time. A solvolysis reaction between 2-bromo-2-methylbutane and butanol was used as a model system. A product of reaction, a bromide ion, could be detected via halide exchange with $\mathrm{CsPbI}_{3}$, by way of a quantitative blue shift $(\Delta \lambda)$ in photoluminescence. The kinetics of this shift was calibrated against a known $\mathrm{Br}^{-}$source, which allowed for conversion to apparent values solvation kinetics. The observed rate constants $(k)$ and corresponding activation energies $(E a)$ measured via the $\mathrm{CsPbI}_{3}$ probe were consistent with literature values for the reaction, confirming the validity of the approach.
\end{abstract}

\section{KEYWORDS}

Cesium Lead Halide, Colorimetric, Perovskite, Assay, Chemical Kinetics, Organohalide 


\section{INTRODUCTION}

Spectrophotometric chemical probes play important roles in assay development and sensor applications, and there is a wide array of examples where color change is based on target coordination, redox, absorption/desorption, or energy transfer processes. ${ }^{1-5}$ Colorimetric assays include UV-visible absorption change, ${ }^{6}$ fluorescence, ${ }^{7}$ bioluminescence, ${ }^{8,9}$ or chemiluminescence, ${ }^{10,11}$ wavelength and or intensity changes. A complement to molecular probes is a growing assortment of nanoparticles that are used as colorimetric assays, such as noble metal particles undergoing surface plasmon resonance (SPR) shifts ${ }^{12,13,7}$ in the presence of biological or organic targets. ${ }^{14-21,7,22-25}$ Quantum dots (QDs) have also been used in a wide number of photoluminescence based sensing, especially those that take advantage of FRET. ${ }^{26}$ Similar work has been shown for 1D nanosheets, like $\mathrm{MoS}_{2},{ }^{27}$ in which novel absorption properties can be coupled with the redox active surface. In addition, bio-nano conjugates can combine molecular assaying with optoelectronic signaling, like quantum rod (QR) based FRET ${ }^{28}$ and BRET. ${ }^{29-32}$ In addition to these, a number of chemical indicators and enzymatic probes have been developed to not only detect a target, but to allow for monitoring of chemical reactions. ${ }^{33,34}$

Metal halide based perovskite nanoparticles, ${ }^{35}$ like methylammonium lead halides $\left(\mathrm{MaPbX}_{3}\right),{ }^{36}$ and cesium lead halides $\left(\mathrm{CsPbX}_{3}, \mathrm{X}=\mathrm{F}, \mathrm{Cl}, \mathrm{Br}, \mathrm{I}\right),{ }^{37-41}$ have a number of properties that may prove useful in colorimetric sensing. For instance, the optoelectronic properties are similar to QDs, but with a few interesting differences. Like QDs, optoelectronic properties are quantum confined and both size and composition tunable, 
42,43,36 with $\mathrm{MaPbX}_{3}$ or $\mathrm{CsPbX}_{3}$ being particularly sensitive to small changes in stoichiometry. This is best illustrated with the facile halide exchange (HE) observed in these systems, when for example, $\mathrm{CsPbI}_{3}$ are reacted with a $\mathrm{Br}^{-}$source forming $\mathrm{CsPbI}_{3-\mathrm{x}} \mathrm{Br}_{\mathrm{x}}$, or when $\mathrm{CsPbBr}_{3}$ is reacted with an excess of $\mathrm{I}^{-}$, resulting in $\mathrm{CsPbBr}_{3-\mathrm{x}} \mathrm{I}_{\mathrm{x}}$. Such stoichiometry differences result in significant $(>100 \mathrm{~nm})$ blue-, and red-shifts, respectfully. While chalcogenide QDs have also been demonstrated to experience ionexchange ${ }^{44}$ for instance, the exchange in perovskites is more rapid due to the fast migration of anion vacancies through the lattice, and the fast exchange of oleylammonium-halide passivating ligands on and off the surface..$^{37,45,46}$ Cation exchange is also possible, and observed to be a significantly slower process, with results being shown for $\mathrm{Pb}^{2+}, \mathrm{Cd}^{2+}, \mathrm{Sn}^{2+}$, and $\mathrm{Zn}^{2+}{ }^{11,12}$

Interestingly, perovskite oxides have a long history as a material for sensing ${ }^{47-52}$ as well as substrates in catalysis, ${ }^{53-56}$ and emerging materials in batteries ${ }^{57}$ However the true potential of using $\mathrm{MaPBX}_{3}$ or $\mathrm{CsPbX}_{3}$ in catalysis, sensor, and assays development is just emerging. ${ }^{58-62}$ For instance, it has been shown that thin films of $\mathrm{CsPBr}_{3}$ can undergo $\mathrm{HE}$ when exposed to $\mathrm{HCl}$ vapors and monitored optically via photoluminescnecne (PL) emission wavelength shift and intensity fluctuation. ${ }^{58}$

We recently explored how $\mathrm{CsPbX}_{3}$ could be used as halide reservoirs for catalysts in organic reactions ${ }^{63}$ In that work the $\mathrm{CsPbX}_{3}$ participated in the reaction as a reactant, but served as an inspiration for the development of a colorimetric assay that could be used to monitor a chemical reaction. Herein, we demonstrate that $\mathrm{CsPbI}_{3}$ nanoparticles undergo a 
photoluminescence shift when reacted with aliquots of a reaction medium. We correlate these PL shifts with ion concentration, which allows us to directly monitor reaction kinetics. The extracted rate constants and activation energies correlate with reported values for this model reaction.

\section{EXPERIMENTAL}

Chemicals and Reagents: Lead (II) iodide (99\%), cesium carbonate (97\%), octadecene (90\%), oleic acid (90\%), oleylamine (70\%), methanol (99.8\%), 1-butanol (anhydrous, $99.8 \%$ ) potassium bromide (99\%), hydrobromic acid (48\%), and 2-bromo-2-methylbutane were purchased from Sigma Aldrich. Hexanes (reagent grade, $95.5 \%$ ) and acetone (reagent grade, $99.5 \%$ ) were purchased from BDH. Dimethyl sulfoxide (99.9\%) and potassium hydroxide $(88.1 \%)$ were purchased from Fisher Scientific, and ethanol (200 proof) was purchased from Pharmco-AAPER. All chemicals were used without further purification.

Instrumentation: UV-Vis spectra were measured with a Cary 50 Bio UV-Vis spectrophotometer and PL emission was measured using a Horiba Jobin Yvon Fluoromax-4 spectrophotometer Time correlated PL spectra were recorded using a Cary 100 Bio.

CsPbI $\mathrm{P}_{3}$ Synthesis: The synthesis of the $\mathrm{CsPbI}_{3}$ nanoparticles used for assaying follows a previously published protocol. ${ }^{37}$ Briefly, $84 \mathrm{mg}$ of lead iodide was mixed with $5 \mathrm{~mL}$ of octadecene and was heated under vacuum at $120^{\circ} \mathrm{C}$ for 40 minutes with mild stirring. After drying, the vessel was placed under inert Ar atmosphere and $0.5 \mathrm{~mL}$ of oleylamine and $0.5 \mathrm{~mL}$ of oleic acid were injected into the solution. The reaction was allowed to mix until all of the solid was dissolved yielding a faint yellow solution. The temperature was raised to $140^{\circ} \mathrm{C}$ and allowed to equilibrate. A premade solution of $0.125 \mathrm{M}$ cesium oleate was heated to $\sim 80^{\circ} \mathrm{C}$ and then $0.4 \mathrm{~mL}$ of this solution was rapidly injected. Upon injection the solution turned a dark red and was immediately quenched in a water 
bath. During cooling, the reaction was removed in $1 \mathrm{~mL}$ aliquots and added to pre-degassed vials containing $20 \mathrm{~mL}$ of hexanes. The vials were then stored in the fridge with desiccant and used as required.

Purification: A $1 \mathrm{~mL}$ sample of the stock $\mathrm{CsPbI}_{3}$ Perovskite solution was taken and placed in an Eppendorf tube. The tube was then centrifuged at 5,000 rpm $(1844 \times g)$ for $1 \mathrm{~min}$. to remove large aggregates. The supernatant was transferred and evaporated to $0.2 \mathrm{~mL}$ under an $\mathrm{Ar}$ stream. 1-BuOH was added to reach a total volume of $1.5 \mathrm{~mL}$, the tube was vortexed for $6 \mathrm{~s}$ and immediately centrifuged at $10,000 \mathrm{rpm}(7378 \times g)$ for $1 \mathrm{~min}$. The supernatant then was decanted and the pellet was dried under an Ar stream for 12s to remove excess leftover butanol. The NP pellet was resuspended in $1 \mathrm{~mL}$ of hexanes. An optimal 30nM concentration of NP was achieved by diluting the cleaned stock. The concentration was determined using an extinction coefficient of $6.4 \times 10^{6} \mathrm{M}^{-}$ ${ }^{1} \mathrm{~cm}^{-1}$ at $425 \mathrm{~nm}^{45}$ and Beer-Lambert's Law.

Assay: A $25 \mathrm{~mL}$ four-necked round bottom flask with a condenser was loaded with 10mL of 1$\mathrm{BuOH}$ and heated to the target temperature. Subsequently, $12.8 \mu \mathrm{L}$ of 2-bromo-2-methylbutane were added to the flask to yield a $10 \mathrm{mM}$ solution. During the reaction a $100 \mu \mathrm{L}$ reaction aliquot was collected and immediately cooled. Next, $2.5 \mu \mathrm{L}$ of this aliquot was injected into the NP assay $\left(700 \mu \mathrm{L},\left[\mathrm{CsPbI}_{3}\right]=30-40 \mathrm{nM}\right)$ vortexed, and allowed to equilibrate for 3 minutes before PL measurement with a Cary Eclipse fluorimeter at and excitation wavelength of $385 \mathrm{~nm}$. 


\section{RESULTS AND DISCUSSION}

Figure 1a illustrates the chemical reaction (i) and $\mathrm{CsPbI}_{3}$ assay approach used in this study (ii). In the assay, a small liquid aliquot is sampled from an organohalide reaction (i) between 2-bromo-2methylbutane (denoted as $\mathrm{S}$ ) with 1-butanol $(\mathrm{BuOH})$. As this solvolysis reaction proceeds, the products, tert-amyl butyl ether (denoted as $\mathrm{P}$ ), protons $\left(\mathrm{H}^{+}\right)$and bromide ions $\left(\mathrm{Br}^{-}\right)$ions continually increase in concentration and is detected by reaction with a known concentration of $\mathrm{CsPbI}_{3} \mathrm{NP}$ assay solution (ii), by way of PL shift $(\Delta \lambda)$.

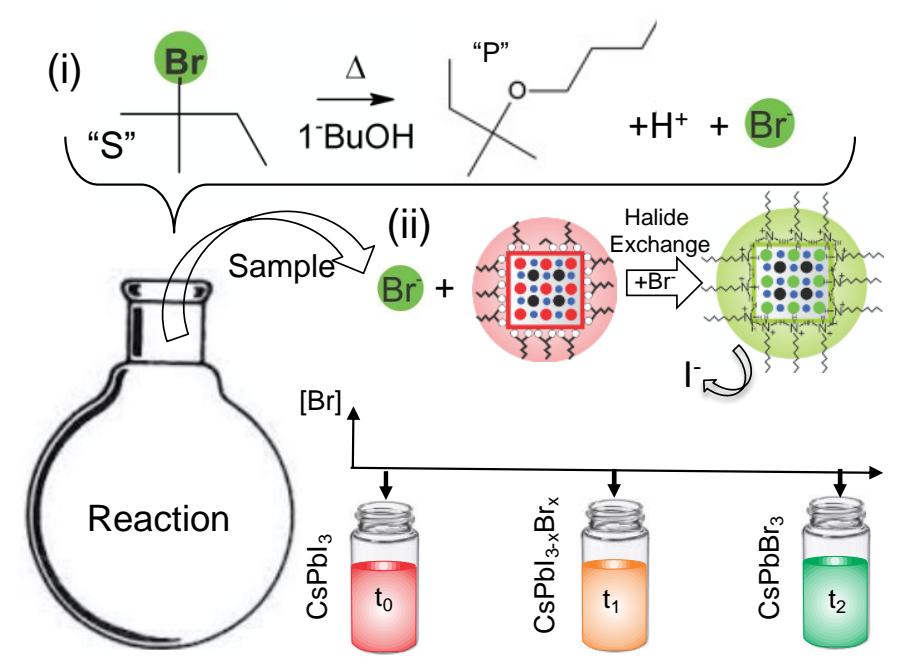

Scheme 1: (i) The solvation reaction between substrate 2-bromo-2-methylbutane (S) and solvent $1-\mathrm{BuOH}$. (ii). Illustration of the assay in operation, where an aliquot of the reaction solution is sampled and then mixed with the $\mathrm{CsPbI} 3$ assay, resulting in halide exchange (HE) and a quantitative PL color shift.

Figure 1a shows a representative set of $\mathrm{CsPbI}_{3}$ absorbance (i) and PL emission spectra (ii). The $\mathrm{CsPBI}_{3}$ were synthesized following reported methods, ${ }^{37}$ with modifications to the purification protocol recently described. ${ }^{46}$ The $\mathrm{CsPbI}_{3}$ were quantified using a reported extinction coefficient of $\varepsilon_{425} \mathrm{~nm}=6.4 \times 10^{6} \mathrm{M}^{-1} \mathrm{~cm}^{-1},{ }^{45,46}$ and showed strong photoluminescence at $662 \mathrm{~nm}$. Before use in the assay, the $\mathrm{CsPbI}_{3}$ ion exchange response 
was calibrated using known concentrations of either $\mathrm{HBr}$ or $\mathrm{TOABr} .{ }^{63}$ Figure $1 \mathrm{~b}$ shows a typical PL response, where increasing $\left[\mathrm{Br}^{-}\right]$in the presence of $\mathrm{CsPbI}_{3}$ causes a $\Delta \lambda$ up to 90 $\mathrm{nm}$ for the concentrations ranged probed in this study.
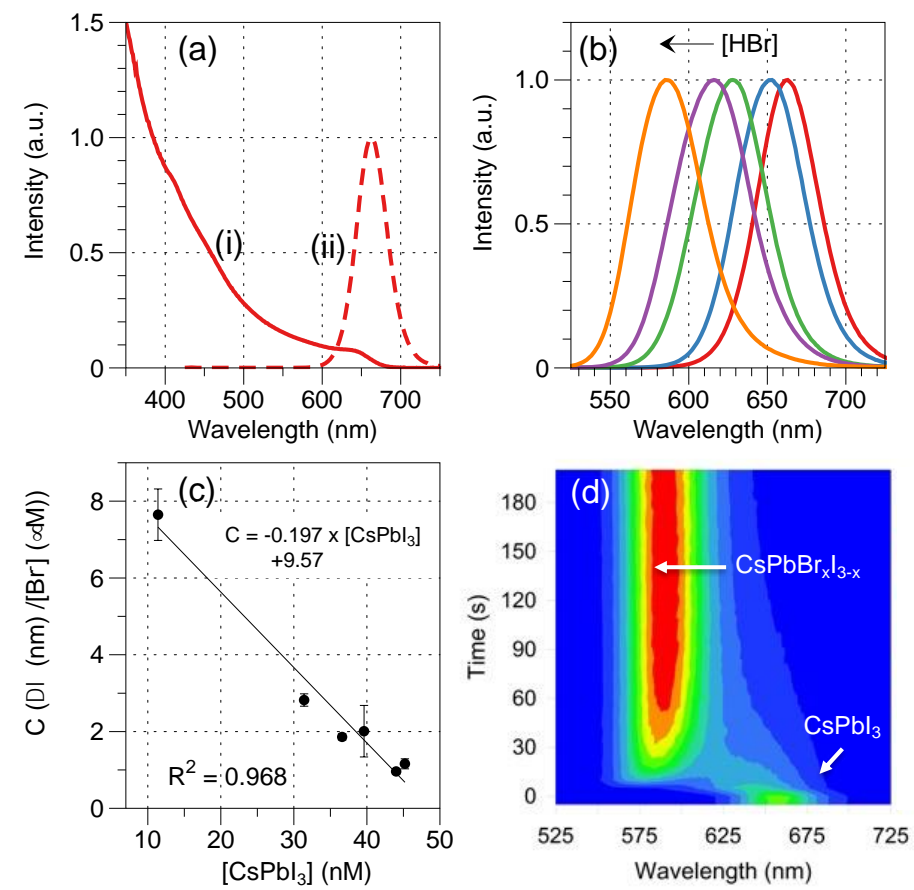

Figure 1: (a) Representative UV-vis (i) and PL emission (ii) of $\mathrm{CsPbI}_{3}$ in hexane. (c) PL shift calibration using $\mathrm{HBr}$ dissolved in $\mathrm{BuOH}$. (c) Calibration plot used in this assay (d), where the $\mathrm{x}$ axis is $\mathrm{CsPbI}_{3}$ concentration in nanomolar units, and the y-axis is the determined sensitivity parameter $\mathrm{C}$, which relates expected PL shift $(\Delta \lambda)$ with accessible $\mathrm{Br}$ - concentrations ([Br-]) in micro molar concentrations. (d) Temporal monitoring of $\Delta \lambda$ during $\mathrm{HE}\left(\left[\mathrm{CsPbI}_{3}\right]=44 \mathrm{nM},[\mathrm{HBr}]\right.$ $=92 \mu \mathrm{M})$.

Figure 1c shows a colorimetric calibration curve, showing a linear correlation between particle concentration, PL shift, and $\mathrm{Br}^{-}$concentration. The $\mathrm{y}$-axis in the plot is the calibration factor (denoted as C) and is in units of nanometers (from PL shift, $\Delta \lambda$ ) and $\mathrm{Br}^{-}$concentration $(\mu \mathrm{M})$. For instance, if the assay is using a $30 \mathrm{nM}$ solution of $\mathrm{CsPbI}_{3}$, then one can expect a $3.66 \mathrm{~nm}$ shift in PL emission per $\mathrm{uM}$ of $\mathrm{Br}^{-}$added to the solution. It is important to note that care must be made to add sufficient $\left[\mathrm{CsPbI}_{3}\right]$ to not rapidly saturate the ion-exchange response (i.e., low $\left[\mathrm{CsPb}_{3}\right]$ 
compared to high $\left.\left[\mathrm{Br}^{-}\right]\right)$. In this study, $\left[\mathrm{CsPbI}_{3}\right]$ was kept between $20-40 \mathrm{nM}$. One limitation of this approach is that the value of $\mathrm{C}$ is influenced by the size of the $\mathrm{CsPbI}_{3}$ nanoparticle used requiring an additional correction (see Fig. S1) ${ }^{64,65}$ Empirically, we found that the correlation of $\left[\mathrm{Br}^{-}\right]$to $\Delta \lambda$ is linear up to $\sim 80 \% \mathrm{Br}^{-}$exchange (i.e., $\mathrm{CsPb}_{0.2} \mathrm{Br}_{0.8}, \Delta \lambda=122 \mathrm{~nm}$ ), at which point ion equilibrium between $\mathrm{I}^{-}$and $\mathrm{Br}^{-}$plays a more direct role in exchange dynamics. In addition, we studied the colorimetric response time for each data point in order to quantify the time needed for full exchange before measuring PL. Figure 1e shows that the assay response is essentially complete at 180s. However, earlier times may also provide a good indicator of $\left[\mathrm{Br}^{-}\right]$as most of the exchange takes place within the first $60 \mathrm{~s}$.
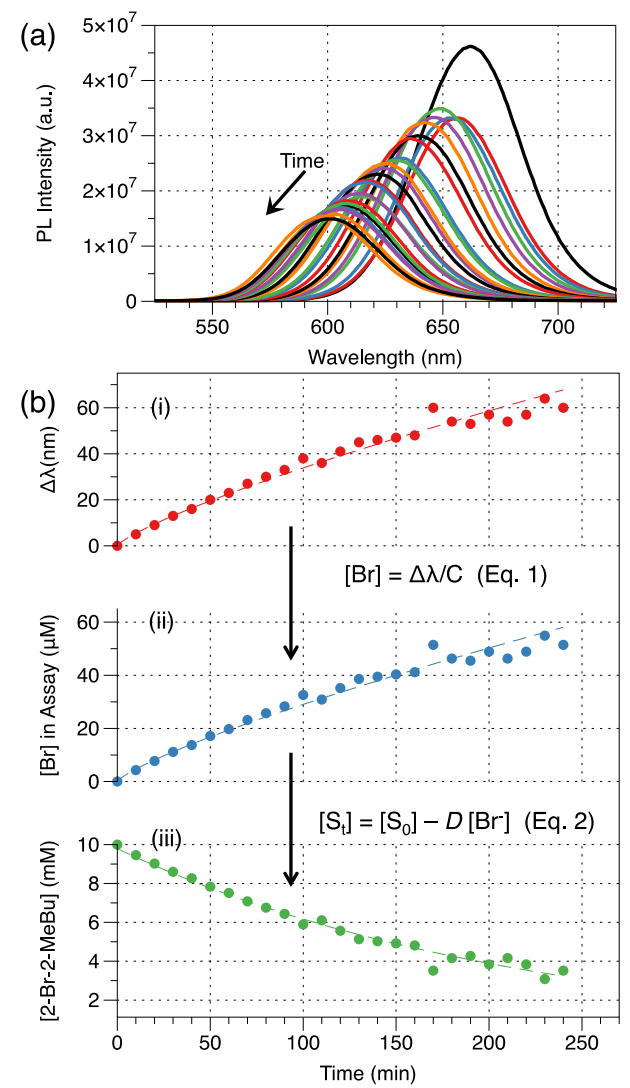

Figure 2: (a) Representative PL spectra of $\mathrm{CsPbI}_{3}$ assay during the reaction monitoring. (b) Plots showing the corresponding PL shift $(\Delta \lambda, \mathrm{b}-\mathrm{i})$, which is converted to [Br-] using equation $1(\mathrm{~b}-\mathrm{ii}, C=1.302 \mathrm{~nm} / \mu \mathrm{M})$. Finally, $\left[\mathrm{Br}^{-}\right]$is converted to $[\mathrm{S}]$ decrease using and equation 2 (dilution factor, $D=126$ ). 
Figure 2 shows a representative workflow for this assay, where the PL response after each aliquot is measured as a function of time. In practicality, this included careful sampling of the reaction vessel as precise volumes, and adding it to a cuvette with a known $\left[\mathrm{CsPb}_{3}\right]$. In this study, the reaction was at $50^{\circ} \mathrm{C}$, while the assay was performed at room temperature.

Next, these PL values were converted to free $\left[\mathrm{Br}^{-}\right]$via equation 1:

$$
C=\frac{(n m)}{[B r](M)}
$$

as shown in Fig. 2b-ii. In this conversion, a $C$ value of $1.302 \mathrm{~nm} / \mu \mathrm{M} \mathrm{Br}^{-}$was used, due to the $[\mathrm{CsPbI}]=46 \mathrm{nM}$. This $\left[\mathrm{Br}^{-}\right]$could then be converted to product formation (an equimolar amount, Fig. 1a), by:

$$
[\mathrm{S}]_{\mathrm{t}}=[\mathrm{S}]_{0}-D\left[\mathrm{Br}^{-}\right]_{\mathrm{t}}
$$

where $\left[\mathrm{Br}^{-}\right]_{\mathrm{t}}$ is the $\mathrm{Br}^{-}$concentration at the assay time point, and $D$ is the corresponding dilution factor used in the transfer of reaction to the assay. In this system, a $2.5 \mu$ aliquot of the reaction medium was reacted with $0.7 \mathrm{ml}$ of $\mathrm{CsPbI}_{3}$ solution. Figure $2 \mathrm{~b}$-iii show the assay result, namely the kinetic trace for the decrease in $[\mathrm{S}]$ as a function of time.

Using the above procedure, the reaction was monitored at several temperatures $(\mathrm{T})$ from $50-70^{\circ} \mathrm{C}$, as shown in Figure 3a i-v. In a control study, the $\mathrm{CsPbI}_{3}$ showed negligible $\Delta \lambda$ in the presence of S alone (see Fig. S2) under these conditions, confirming that PL change is due to the solvolysis reaction and not a halide exchange between $\mathrm{S}$ and $\mathrm{CsPbI}$, 
a Finkelstein reaction, as we have shown previously. ${ }^{63}$ Interestingly, each of the reactions reach an expected equilibrium concentration of $\mathrm{S}$, which indicate that the buildup of $\mathrm{Br}^{-}$ (formation of $\mathrm{HBr}$ ) promotes acid catalyzed ether cleavage and re-generate $\mathrm{S}$, as has been reported for other tertiary ethers under anhydrous conditions. ${ }^{66,67}$ Repeating the experiment three times confirmed that equilibrium was established (Figure 3a (iv-v), error bars) and shows that the assay is reproducible.
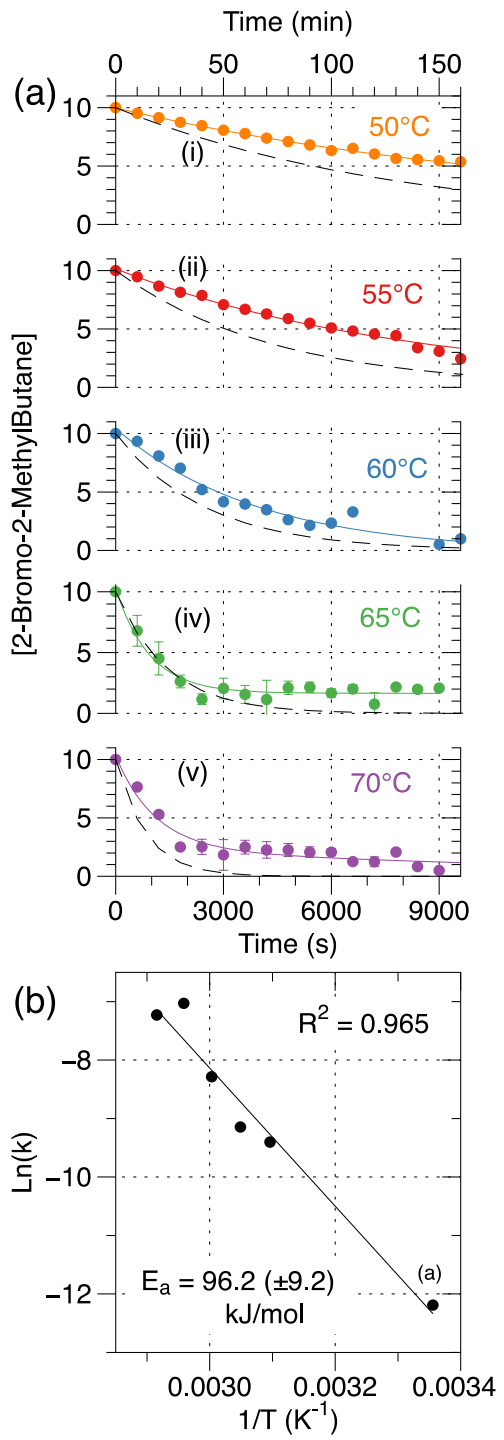

Figure 3: (a) Kinetic traces using $\mathrm{CsPbI}_{3}$ assay from reactions occurring at $\mathrm{T}=$ (i) 50, (ii) 55, (iii) 60 , (iv) 65 and (v) $70^{\circ} \mathrm{C}$. The dashed lines indicate the calculated kinetics using a literature values for the activation energy, $E_{a}$ and pre-exponential factor $A$ obtained from a rate constant at $25^{\circ} \mathrm{C} .{ }^{68}$ 
(b) An Arrhenius Plot of $\operatorname{Ln}(k)$ vs. 1/T used to calculate $E_{a}$ for the reaction. For additional information and fitting parameters and representative spectra, see Table S1-S2, and Fig. S3.

Next, the reaction rate constant, $k$, was extracted from the final kinetic plots, which for an $S_{N} 1$ reaction like this one, obeys a first order rate law with respect to [S] by:

$$
\mathrm{d}[\mathrm{S}] / d t=e^{-k t}
$$

where $k$ is the apparent rate constant at a given T. The data in Figure 3 a were fit to a single exponential decay (Table S1) from which the rate constants were found (Table S2). For reference, the predicted solvolysis rates based on literature values of $E_{a}$ of $103.3 \mathrm{~kJ}$ and a pre-exponential factor, $A$ of $6.626 \times 10^{18}$ are shown as dashed lines in Figure $3 a^{68}$ At higher temperatures, the acid catalyzed tertiary ether cleavage has been proposed to be a bimolecular reaction which obeys second order kinetics but is governed by a slow $\mathrm{R}_{3} \mathrm{C}$ $\mathrm{OH}^{+}-\mathrm{R}$ rearrangement. ${ }^{69}$ Assuming the rearrangement is the slowest step, the kinetic rate relationship can be approximated in the steady state condition as a pseudo reversible first order reaction given as:

$$
[S]=\frac{k_{2}\left[A_{0}\right]}{k_{1}+k_{1}}\left[1+\frac{k_{1}}{k_{2}} e^{-\left(k_{1}+k_{2}\right) t}\right]
$$

where $k_{1}$ is the rate for solvolysis of $S$ to form $\mathrm{P}$ and $k_{2}$ is the rate for $\mathrm{HBr}$ mediated cleavage of n-butyl tert amyl ether to regenerate $[S]$. Focusing on the higher temperature reactions, and fitting the data in Fig 3a-iv with a single exponential and rearranging terms, we find that $k_{1}=884.7 \times 10^{-6} \mathrm{~s}$ and $k_{2}=174.6 \times 10^{-6} \mathrm{~s}($ see Table $\mathrm{S} 1-\mathrm{S} 2)$. At $70^{\circ} \mathrm{C}($ Fig. $3 \mathrm{a}-\mathrm{v})$, a biexponential rate function was the best fit, with a fast component of $k_{f a s t}=923.1 \times 10^{-6} \mathrm{~s}$ and $k_{\text {slow }}=77.9 \times 10^{-6} \mathrm{~s}$, suggesting that the forward reaction becomes more competitive at 
$70^{\circ} \mathrm{C}$. Fitting the region between 0 and 3600s with a single exponential and using Eqn 4, we find that $k_{1}=725.4 \times 10^{-6} \mathrm{~s}$ and $k_{2}=162.22 \times 10^{-6} \mathrm{~s}$. The decrease in rate at higher temperatures may also reflect more complex rate behavior due to intermediates not accounted for in the steady state hypothesis during alkylhalide sovolysis, ${ }^{70,71}$ which seems likely given the slower decay component at $70^{\circ} \mathrm{C}$.

To further validate the $\mathrm{CsPbI}_{3}$ assay approach to monitoring these reaction kinetics, the extracted $k$ values were plotted as a function of temperature (Fig. 3b) and fit according to the Arrhenius relationship:

$$
\mathrm{k}=A e^{(-E a / \mathrm{RT})}
$$

where $E_{\mathrm{a}}$ is the activation energy for the reaction, and $A$ is the pre-exponential factor. The plot shows a linear relationship (Figure 3b), from which we can extract an $E_{\mathrm{a}}$ of $96.3 \pm 8.0$ $\mathrm{kJ} / \mathrm{mol}$. Previous NMR based studies of solvolysis of $\mathrm{S}$ in 1-butanol at $25^{\circ} \mathrm{C}$ using found a rate constant of $k=5.02 \times 10^{-6} \mathrm{~s}^{-1}$ and a corresponding activation energy of $103.3 \mathrm{~kJ} / \mathrm{mol},{ }^{68}$ which are similar to other estimates of $E_{\mathrm{a}}$ for the solvolysis of tert-butyl bromide. ${ }^{72}$ which is in reasonable agreement with these $\mathrm{CsPbI}_{3} \mathrm{NP}$ based assay results.

\section{CONCLUSION}

Taken together these results indicate that halide exchange in perovskite nanoparticles can be used as colorimetric chemical assays. In this system, $\mathrm{CsPbI}_{3}$ nanoparticles serve as colorimetric probes of an organic reaction by measuring one of the bi-products, a $\mathrm{Br}^{-}$ion. 
By reacting this ion with the $\mathrm{CsPbI}_{3}$, a change in composition to $\mathrm{CsPbI}_{3-\mathrm{x}} \mathrm{Br}_{\mathrm{x}}$ occurs, leading to a quantitative shift in photoluminescence. This shift is thus a proxy for the chemical reaction, and can be used monitor reaction rates and corresponding activation energies of these reaction. While the presented assay is a model system prototype, future studies monitoring a number of relevant organo halide based reactions are possible, as well as is the possibility of developing colorimetric assays for halide containing compounds.

\section{ASSOCIATED CONTENT}

Supporting information related to kinetic trace fitting, control experiments, and full PL spectra are available in Table S1-S2 and Figure S1-S3.

\section{AUTHOR INFORMATION}

\section{Corresponding Author}

*mmmaye@syr.edu

\section{Notes}

The authors declare no competing financial interests.

\section{ACKNOWLEDGMENT}

This work was partially supported via a NSF MRI grant (DBI-1531757), a NSF DMR grant (DMR1410569). 


\section{REFERENCES}

(1) Zhang, J. F.; Zhou, Y.; Yoon, J.; Kim, J. S. Recent Progress in Fluorescent and Colorimetric Chemosensors for Detection of Precious Metal Ions (Silver, Gold and Platinum Ions). Chem. Soc. Rev. 2011, 40 (7), 3416.

(2) Chen, X.; Zhou, Y.; Peng, X.; Yoon, J. Fluorescent and Colorimetric Probes for Detection of Thiols. Chem. Soc. Rev. 2010, 39 (6), 2120.

(3) Kim, H. N.; Ren, W. X.; Kim, J. S.; Yoon, J. Fluorescent and Colorimetric Sensors for Detection of Lead, Cadmium, and Mercury Ions. Chem Soc Rev 2012, 41 (8), 3210-3244.

(4) Zhu, H.; Fan, J.; Wang, B.; Peng, X. Fluorescent, MRI, and Colorimetric Chemical Sensors for the First-Row D-Block Metal Ions. Chem. Soc. Rev. 2015, 44 (13), 4337-4366.

(5) Askim, J. R.; Mahmoudi, M.; Suslick, K. S. Optical Sensor Arrays for Chemical Sensing: The Optoelectronic Nose. Chem. Soc. Rev. 2013, 42 (22), 8649.

(6) Elghanian, R.; Storhoff, J. J.; Mucic, R. C.; Letsinger, R. L.; Mirkin, C. A. Selective Colorimetric Detection of Polynucleotides Based on the Distance-Dependent Optical Properties of Gold Nanoparticles. Science 1997, 277 (5329), 1078-1081.

(7) Heo, J. H.; Yi, G. S.; Lee, B. S.; Cho, H. H.; Lee, J. W.; Lee, J. H. A Significant Enhancement of Color Transition from an On-off Type Achromatic Colorimetric Nanosensor for Highly Sensitive Multi-Analyte Detection with the Naked Eye. Nanoscale 2016, 8 (43), 18341-18351.

(8) Shinde, R.; Perkins, J.; Contag, C. H. Luciferin Derivatives for Enhanced in Vitro and in Vivo Bioluminescence Assays ${ }^{\dagger}$. Biochemistry (Mosc.) 2006, 45 (37), 11103-11112.

(9) Yoshida, W.; Baba, Y.; Karube, I. Global DNA Methylation Detection System Using MBDFused Luciferase Based on Bioluminescence Resonance Energy Transfer Assay. Anal. Chem. 2016, 88 (18), 9264-9268.

(10) Cheek, B. J.; Steel, A. B.; Torres, M. P.; Yu, Y.-Y.; Yang, H. Chemiluminescence Detection for Hybridization Assays on the Flow-Thru Chip, a Three-Dimensional Microchannel Biochip. Anal. Chem. 2001, 73 (24), 5777-5783.

(11) Yan, Y.; Yue, S.; Zhao, T.; Luo, B.; Bi, S. Exonuclease-Assisted Target Recycling Amplification for Label-Free Chemiluminescence Assay and Molecular Logic Operations. Chem. Commun. 2017, 53 (90), 12201-12204.

(12) Breger, J. C.; Ancona, M. G.; Walper, S. A.; Oh, E.; Susumu, K.; Stewart, M. H.; Deschamps, J. R.; Medintz, I. L. Understanding How Nanoparticle Attachment Enhances Phosphotriesterase Kinetic Efficiency. ACS Nano 2015, 9 (8), 8491-8503.

(13) Xie, X.; Xu, W.; Liu, X. Improving Colorimetric Assays through Protein Enzyme-Assisted Gold Nanoparticle Amplification. Acc. Chem. Res. 2012, 45 (9), 1511-1520.

(14) Mirkin, C. A.; Letsinger, R. L.; Mucic, R. C.; Storhoff, J. J. A DNA-Based Method for Rationally Assembling Nanoparticles into Macroscopic Materials. Nature 1996, 382, 607609.

(15) Lim, I.-I. S.; Ip, W.; Crew, E.; Njoki, P. N.; Mott, D.; Zhong, C.-J.; Pan, Y.; Zhou, S. Homocysteine-Mediated Reactivity and Assembly of Gold Nanoparticles. Langmuir 2007, 23 (2), 826-833.

(16) Lim, S. I.; Zhong, C.-J. Molecularly Mediated Processing and Assembly of Nanoparticles: Exploring the Interparticle Interactions and Structures. Acc. Chem. Res. 2009, 42 (6), 798808. 
(17) Zhang, F. X.; Han, L.; Israel, L. B.; Daras, J. G.; Maye, M. M.; K. Ly, N.; Zhong, C.-J. Colorimetric Detection of Thiol-Containing Amino Acids Using Gold Nanoparticles. The Analyst 2002, 127 (4), 462-465.

(18) Chen, Y.; Xianyu, Y.; Jiang, X. Surface Modification of Gold Nanoparticles with Small Molecules for Biochemical Analysis. Acc. Chem. Res. 2017, 50 (2), 310-319.

(19) Xia, Z.; Xing, Y.; So, M.-K.; Koh, A. L.; Sinclair, R.; Rao, J. Multiplex Detection of Protease Activity with Quantum Dot Nanosensors Prepared by Intein-Mediated Specific Bioconjugation. Anal. Chem. 2008, 80 (22), 8649-8655.

(20) Kim, H. Y.; Choi, I. Ultrafast Colorimetric Determination of Predominant Protein Structure Evolution with Gold Nanoplasmonic Particles. Nanoscale 2016, 8 (4), 1952-1959.

(21) Uehara, N. Colorimetric Assay of Homocysteine Using Gold Nanoparticles Conjugated with Thermoresponsive Copolymers. Anal Methods 2016, 8 (39), 7185-7192.

(22) Kim, B.-H.; Yoon, I. S.; Lee, J.-S. Masking Nanoparticle Surfaces for Sensitive and Selective Colorimetric Detection of Proteins. Anal. Chem. 2013, 85 (21), 10542-10548.

(23) Li, B.; Li, X.; Dong, Y.; Wang, B.; Li, D.; Shi, Y.; Wu, Y. Colorimetric Sensor Array Based on Gold Nanoparticles with Diverse Surface Charges for Microorganisms Identification. Anal. Chem. 2017, 89 (20), 10639-10643.

(24) Xu, H.; Hepel, M. "Molecular Beacon"-Based Fluorescent Assay for Selective Detection of Glutathione and Cysteine. Anal. Chem. 2011, 83 (3), 813-819.

(25) Ofir, Y.; Samanta, B.; Rotello, V. M. Polymer and Biopolymer Mediated Self-Assembly of Gold Nanoparticles. Chem. Soc. Rev. 2008, 37 (9), 1814.

(26) Boeneman, K.; Deschamps, J. R.; Buckhout-White, S.; Prasuhn, D. E.; Blanco-Canosa, J. B.; Dawson, P. E.; Stewart, M. H.; Susumu, K.; Goldman, E. R.; Ancona, M.; et al. Quantum Dot DNA Bioconjugates: Attachment Chemistry Strongly Influences the Resulting Composite Architecture. ACS Nano 2010, 4 (12), 7253-7266.

(27) Hizir, M. S.; Robertson, N. M.; Balcioglu, M.; Alp, E.; Rana, M.; Yigit, M. V. Universal Sensor Array for Highly Selective System Identification Using Two-Dimensional Nanoparticles. Chem. Sci. 2017, 8 (8), 5735-5745.

(28) Doane, T. L.; Alam, R.; Maye, M. M. Functionalization of Quantum Tods with Oligonucleotides for Programmable Assembly with DNA Origami. Nanoscale 2015, 7, 2883-2888.

(29) Alam, R.; Fontaine, D. M.; Branchini, B. R.; Maye, M. M. Designing Quantum Rods for Optimized Energy Transfer with Firefly Luciferase Enzymes. Nano Lett. 2012, 12 (6), 3251-3256.

(30) Alam, R.; Zylstra, J.; Fontaine, D. M.; Branchini, B. R.; Maye, M. M. Novel Multistep BRET-FRET Energy Transfer Using Nanoconjugates of Firefly Proteins, Quantum Dots, and Red Fluorescent Proteins. Nanoscale 2013, 5 (12), 5303.

(31) Alam, R.; Karam, L. M.; Doane, T. L.; Coopersmith, K.; Fontaine, D. M.; Branchini, B. R.; Maye, M. M. Probing Bioluminescence Resonance Energy Transfer in Quantum RodLuciferase Nanoconjugates. ACS Nano 2016, 10 (2), 1969-1977.

(32) Alam, R.; Karam, L. M.; Doane, T. L.; Zylstra, J.; Fontaine, D. M.; Branchini, B. R.; Maye, M. M. Near Infrared Bioluminescence Resonance Energy Transfer from Firefly Luciferase — quantum Dot Bionanoconjugates. Nanotechnology 2014, 25 (49), 495606.

(33) Blackmond, D. G. Kinetic Profiling of Catalytic Organic Reactions as a Mechanistic Tool. J. Am. Chem. Soc. 2015, 137 (34), 10852-10866. 
(34) Zhang, X.; Yin, J.; Yoon, J. Recent Advances in Development of Chiral Fluorescent and Colorimetric Sensors. Chem. Rev. 2014, 114 (9), 4918-4959.

(35) Schaak, R. E.; Mallouk, T. E. Prying Apart Ruddlesden-Popper Phases: Exfoliation into Sheets and Nanotubes for Assembly of Perovskite Thin Films. Chem. Mater. 2000, 12 (11), 3427-3434.

(36) Schmidt, L. C.; Pertegás, A.; González-Carrero, S.; Malinkiewicz, O.; Agouram, S.; Mínguez Espallargas, G.; Bolink, H. J.; Galian, R. E.; Pérez-Prieto, J. Nontemplate Synthesis of $\mathrm{CH}_{3} \mathrm{NH}_{3} \mathrm{PbBr}_{3}$ Perovskite Nanoparticles. J. Am. Chem. Soc. 2014, 136 (3), 850-853.

(37) Protesescu, L.; Yakunin, S.; Bodnarchuk, M. I.; Krieg, F.; Caputo, R.; Hendon, C. H.; Yang, R. X.; Walsh, A.; Kovalenko, M. V. Nanocrystals of Cesium Lead Halide Perovskites $\left(\mathrm{CsPbX}_{3}, \mathrm{X}=\mathrm{Cl}, \mathrm{Br}\right.$, and I): Novel Optoelectronic Materials Showing Bright Emission with Wide Color Gamut. Nano Lett. 2015, 15 (6), 3692-3696.

(38) Amgar, D.; Aharon, S.; Etgar, L. Inorganic and Hybrid Organo-Metal Perovskite Nanostructures: Synthesis, Properties, and Applications. Adv. Funct. Mater. 2016, 26 (47), 8576-8593.

(39) Akkerman, Q. A.; Abdelhady, A. L.; Manna, L. Zero-Dimensional Cesium Lead Halides: History, Properties, and Challenges. J. Phys. Chem. Lett. 2018, 9 (9), 2326-2337.

(40) Akkerman, Q. A.; D’Innocenzo, V.; Accornero, S.; Scarpellini, A.; Petrozza, A.; Prato, M.; Manna, L. Tuning the Optical Properties of Cesium Lead Halide Perovskite Nanocrystals by Anion Exchange Reactions. J. Am. Chem. Soc. 2015, 137 (32), 10276-10281.

(41) Zhang, D.; Eaton, S. W.; Yu, Y.; Dou, L.; Yang, P. Solution-Phase Synthesis of Cesium Lead Halide Perovskite Nanowires. J. Am. Chem. Soc. 2015, 137 (29), 9230-9233.

(42) Sichert, J. A.; Tong, Y.; Mutz, N.; Vollmer, M.; Fischer, S.; Milowska, K. Z.; García Cortadella, R.; Nickel, B.; Cardenas-Daw, C.; Stolarczyk, J. K.; et al. Quantum Size Effect in Organometal Halide Perovskite Nanoplatelets. Nano Lett. 2015, 15 (10), 6521-6527.

(43) Gong, M.; Zhou, W.; Tsai, M.-C.; Zhou, J.; Guan, M.; Lin, M.-C.; Zhang, B.; Hu, Y.; Wang, D.-Y.; Yang, J.; et al. Nanoscale Nickel Oxide/Nickel Heterostructures for Active Hydrogen Evolution Electrocatalysis. Nat. Commun. 2014, 5 (1).

(44) Luther, J. M.; Zheng, H.; Sadtler, B.; Alivisatos, A. P. Synthesis of PbS Nanorods and Other Ionic Nanocrystals of Complex Morphology by Sequential Cation Exchange Reactions. J. Am. Chem. Soc. 2009, 131 (46), 16851-16857.

(45) Koscher, B. A.; Bronstein, N. D.; Olshansky, J. H.; Bekenstein, Y.; Alivisatos, A. P. Surface- vs Diffusion-Limited Mechanisms of Anion Exchange in $\mathrm{CsPbBr}_{3}$ Nanocrystal Cubes Revealed through Kinetic Studies. J. Am. Chem. Soc. 2016.

(46) De Roo, J.; Ibáñez, M.; Geiregat, P.; Nedelcu, G.; Walravens, W.; Maes, J.; Martins, J. C.; Van Driessche, I.; Kovalenko, M. V.; Hens, Z. Highly Dynamic Ligand Binding and Light Absorption Coefficient of Cesium Lead Bromide Perovskite Nanocrystals. ACS Nano 2016, 10 (2), 2071-2081.

(47) Zhang, Z.; Schwanz, D.; Narayanan, B.; Kotiuga, M.; Dura, J. A.; Cherukara, M.; Zhou, H.; Freeland, J. W.; Li, J.; Sutarto, R.; et al. Perovskite Nickelates as Electric-Field Sensors in Salt Water. Nature 2017, 553 (7686), 68-72.

(48) Obayashi, H.; Sakurai, Y.; Gejo, T. Perovskite-Type Oxides as Ethanol Sensors. J. Solid State Chem. 1976, 17 (3), 299-303.

(49) Fergus, J. W. Perovskite Oxides for Semiconductor-Based Gas Sensors. Sens. Actuators B Chem. 2007, 123 (2), 1169-1179. 
(50) Martinelli, G.; Carotta, M. C.; Ferroni, M.; Sadaoka, Y.; Traversa, E. Screen-Printed Perovskite-Type Thick Films as Gas Sensors for Environmental Monitoring. Sens. Actuators B Chem. 1999, 55, 99-110.

(51) Post, M. L.; Tunney, J. J.; Yang, D.; Du, X.; Singleton, D. L. Material Chemistry of Perovskite Compounds as Chemical Sensors. Sens. Actuators B Chem. 1999, 59 (2-3), 190194.

(52) Torre-Gamarra, C. de la; Woszczak, M.; Levenfeld, B.; Varez, A.; García-González, E.; Urones-Garrote, E.; Di Noto, V. Interplay between Humidity, Temperature and Electrical Response of a Conductivity Sensor Based on a $\mathrm{La}_{2} \mathrm{LiNbO}_{6}$ Double Perovskite. J. Mater. Chem. A 2018, 6 (13), 5430-5442.

(53) Chai, Y.; Fu, Y.; Feng, H.; Kong, W.; Yuan, C.; Pan, B.; Zhang, J.; Sun, Y. A Nickel-Based Perovskite Catalyst with a Bimodal Size Distribution of Nickel Particles for Dry Reforming of Methane. ChemCatChem 2018, 10 (9), 2078-2086.

(54) Lim, C.; Kim, C.; Gwon, O.; Jeong, H. Y.; Song, H.-K.; Ju, Y.-W.; Shin, J.; Kim, G. NanoPerovskite Oxide Prepared via Inverse Microemulsion Mediated Synthesis for Catalyst of Lithium-Air Batteries. Electrochimica Acta 2018, 275, 248-255.

(55) Jeyalakshmi, V.; Mahalakshmy, R.; Krishnamurthy, K. R.; Viswanathan, B. Strontium Titanates with Perovskite Structure as Photo Catalysts for Reduction of CO 2 by Water: Influence of Co-Doping with N, S \& Fe. Catal. Today 2018, 300, 152-159.

(56) Zhu, J.; Li, H.; Zhong, L.; Xiao, P.; Xu, X.; Yang, X.; Zhao, Z.; Li, J. Perovskite Oxides: Preparation, Characterizations, and Applications in Heterogeneous Catalysis. ACS Catal. 2014, 4 (9), 2917-2940.

(57) Xu, J.-J.; Xu, D.; Wang, Z.-L.; Wang, H.-G.; Zhang, L.-L.; Zhang, X.-B. Synthesis of Perovskite-Based Porous La $0.75 \mathrm{Sr} \quad 0.25 \mathrm{MnO}_{3}$ Nanotubes as a Highly Efficient Electrocatalyst for Rechargeable Lithium-Oxygen Batteries. Angew. Chem. Int. Ed. 2013, 52 (14), 3887-3890.

(58) Chen, X.; Hu, H.; Xia, Z.; Gao, W.; Gou, W.; Qu, Y.; Ma, Y. CsPbBr 3 Perovskite Nanocrystals as Highly Selective and Sensitive Spectrochemical Probes for Gaseous $\mathrm{HCl}$ Detection. J Mater Chem C 2017, 5 (2), 309-313.

(59) Ren, K.; Huang, L.; Yue, S.; Lu, S.; Liu, K.; Azam, M.; Wang, Z.; Wei, Z.; Qu, S.; Wang, Z. Turning a Disadvantage into an Advantage: Synthesizing High-Quality Organometallic Halide Perovskite Nanosheet Arrays for Humidity Sensors. J. Mater. Chem. C 2017, 5 (10), 2504-2508.

(60) Saraf, R.; Pu, L.; Maheshwari, V. A Light Harvesting, Self-Powered Monolith Tactile Sensor Based on Electric Field Induced Effects in MAPbI 3 Perovskite. Adv. Mater. 2018, 30 (9), 1705778.

(61) Cao, Y.; Qi, G.; Liu, C.; Wang, L.; Ma, Z.; Wang, K.; Du, F.; Xiao, G.; Zou, B. PressureTailored Band Gap Engineering and Structure Evolution of Cubic Cesium Lead Iodide Perovskite Nanocrystals. J. Phys. Chem. C 2018, 122 (17), 9332-9338.

(62) Ramasamy, P.; Lim, D.-H.; Kim, B.; Lee, S.-H.; Lee, M.-S.; Lee, J.-S. All-Inorganic Cesium Lead Halide Perovskite Nanocrystals for Photodetector Applications. Chem. Commun. 2016, 52 (10), 2067-2070.

(63) Doane, T. L.; Ryan, K. L.; Pathade, L.; Cruz, K. J.; Zang, H.; Cotlet, M.; Maye, M. M. Using Perovskite Nanoparticles as Halide Reservoirs in Catalysis and as Spectrochemical Probes of Ions in Solution. ACS Nano 2016, 10 (6), 5864-5872. 
(64) Zhang, D.; Yang, Y.; Bekenstein, Y.; Yu, Y.; Gibson, N. A.; Wong, A. B.; Eaton, S. W.; Kornienko, N.; Kong, Q.; Lai, M.; et al. Synthesis of Composition Tunable and Highly Luminescent Cesium Lead Halide Nanowires through Anion-Exchange Reactions. J. Am. Chem. Soc. 2016, 138 (23), 7236-7239.

(65) Zhang, D.; Yu, Y.; Bekenstein, Y.; Wong, A. B.; Alivisatos, A. P.; Yang, P. Ultrathin Colloidal Cesium Lead Halide Perovskite Nanowires. J. Am. Chem. Soc. 2016, 138 (40), 13155-13158.

(66) Burwell, R. L. The Cleavage of Ethers. Chem. Rev. 1954, 54 (4), 615-685.

(67) Burwell, R. L.; Fuller, M. E. The Cleavage of Ethers by Hydrogen Bromide. J. Am. Chem. Soc. 1957, 79 (9), 2332-2336.

(68) Albuquerque, L. C.; Moita, L. C.; Gonçalves, R. C.; Macedo, E. A. Kinetics and Activation Thermodynamics of the Solvolysis of Tert-Pentyl and Tert-Hexyl Halides in Alcohols. $J$. Chem. Res. 2002, 2002 (11), 535-536.

(69) Okamoto, K.; Takeuchi, K.; Shingu, H. Kinetic Studies of Solvolysis. IX. The S N L-Type Cleavage of $T$-Butyl $P$-Substituted-Phenyl Ethers and Optically-Active $\alpha$-Phenethyl Phenyl Ether by Hydrogen Halides in a Phenol-Dioxane Solvent. Bull. Chem. Soc. Jpn. 1964, 37 (2), 276-282.

(70) Blandamer, M. J.; Robertson, R. E.; Ralph, E.; Scott, J. M. W. Kinetics of Solvolytic Reactions. Dependence of Composition on Time and of Rate Parameters on Temperature. J. Chem. Soc. Faraday Trans. 1 Phys. Chem. Condens. Phases 1983, 79 (5), 1289.

(71) Scott, J. M. On the Displacement Reactions of Organic Substances in Water. Can. J. Chem. 2005, 83 (9), 1667-1719.

(72) Gonçalves, R. M. C.; Simões, A. M. N.; Albuquerque, L. M. P. C.; Formosinho, S. J. Solvent and Temperature Effects on the Rate Constants of Solvolysis of Tert-Butyl Bromide in Mono- and Di-Alcohols. J Chem Soc Perkin Trans 2 1991, No. 6, 931-935.

(73) Swarnkar, A.; Marshall, A. R.; Sanehira, E. M.; Chernomordik, B. D.; Moore, D. T.; Christians, J. A.; Chakrabarti, T.; Luther, J. M. Quantum Dot-Induced Phase Stabilization of -CsPbI3 Perovskite for High-Efficiency Photovoltaics. Science 2016, 354 (6308), 92-95. 
